\title{
Co-creating and Developing Health Management Theory and Practice: a global opportunity?
}

In recent years much has been made of the need to effectively translate knowledge developed through research into health systems practice. [1] Literature suggests that the acceptance of research findings would be more likely if the research were achieved and disseminated into practice where it occurs in a more collaborative alignment of researchers and practitioners. [2]

Contemporary health policy and practice is indeed calling for more evidence-based research in areas of clinical practice, clinical pathways and in the broad focus on quality and safety of patients in our health systems. What about health management, who leads the way in this space?

The Statement on Advancing Implementation Research and Delivery Science (IRDS) from the Alliance for Health Policy and Systems Research [1] has called for extended use of IRDS 'to better address local, national and global health'. [1, p.1] The statement defines IRDS as 'a type of health policy and systems research that draws on many traditions and disciplines of research and practice.' [1, pp.1-2] The Statement has also called on Editors and publishing organisations to promote and publish around the importance of implementation research and delivery science in health systems.

The call has caused this Editor to pause and reflect on the role of this Journal and that of the Australasian College of Health Services Management (ACHSM), the professional body for health managers. The APJHM is the professional peer reviewed Journal of ACHSM. The Journal is a significant resource for College members but openly available to all health professionals. The College and the Journal both have quite clear commitments and roles in the education and development of health managers and of health leadership capability. Both are involved in the dissemination of knowledge and implementation of best practice in management within and across health systems. [3]

The College, of course, was established many decades ago by health managers of the time, across Australian State boundaries, who were visionary about their role and the need to develop it as a profession in its own right. Similar likeminded and visionary managers and health leaders also demonstrated leadership in the establishment of the Journal more than a decade ago. ACHSM has also extended its role across national boundaries in affiliation with like minded organisations in New Zealand and Hong Kong. This places ACHSM in a unique position to encourage a similar approach to that called for in the IRDS Statement [1] in respect to the management of health systems.

The College in its delivery of education programs, the fellowship process, the mentoring program, the library and the Journal has consistently utilised and engaged the membership, both practising health managers and academics in the delivery of its member services. That utilisation across practitioners and researchers extends across accreditation of tertiary health management programs and publication of texts [4] undertaken in collaboration with the Society for Health Administration in Education (SHAPE), representative of health management academic programs. So the College is well-placed to participate in and develop health management research into knowledge and evidence-based practice.

The Journal extends the collaboration between researchers and health managers and other operational health professionals by publishing research and increasing the participation of College members both operational and as academics, collaboratively through authorship, peer review and management processes of the Journal. It goes further by also utilising others who are non-members in these processes across academic schools that are not traditionally health management and across national health systems boundaries within the Asia Pacific. This is the natural extension in a world where healthcare delivery organisations and government organisations are focused on the performance of their services while the workforce they employ and performance measurement is increasingly globalised.

For example, Health Systems Global claims to be the first international membership organisation to promote 
health systems research and knowledge translation. An organisation created from and launched at the 2014 Global Symposium on Health Systems Research, it now has 1500 members from 96 countries and has established some ten Thematic Working Groups (TWG) of members to address research and knowledge translation approaches through members nominating to join a TWG. This brings together researchers, decision-makers and implementers. There are established criteria and membership requirements with secretariat support but essentially they are self-organising and resourced by members pursuing a common theme. [5]

This is an innovative approach to knowledge translation and learning and it might be useful to reflect on the potential of this approach to establish global networks of practice and learning in leading and managing health systems. The healthcare industry is 'increasingly becoming a knowledge-based community that depends critically on knowledge management (KM) activities.' [6, p.13] Hustad, in a different context than the healthcare industry explored the phenomenon of knowledge networking in distributed work describing the practice as distributed networks of practice (DNoP), a description that extends the concept of a community of practice. [7] Hustad considers communities of practice to be closely knit and connected groups engaged in shared practice, meeting face-to-face and communicating directly, [7, p.69] whereas 'DNoP comprises a larger, geographically dispersed group of participants engaged in a shared practice or common topic of interest'. [7, p.69]

While that article describes networks in a commercial entity across national borders it does also describe problem solving, business improvement and innovation networks. DNoP are described as 'knowledge networking infrastructure' [7, p.77] and as such are likely to be self-organising and emergent, supported by technology and are structures that sit alongside formal organisation structures. Hustad warns organisations wanting to use these approaches to learning to cultivate and sustain their growth by avoiding the imposition of normal organisational control approaches. In fact, another study by Agterberg et al [8, p. 85] emphasises the need to manage DNoP'without killing them'. Van Baalen and colleagues explore the applicability of a knowledge portal as potentially providing the infrastructure and support technology described by Hustad and emphasise that the 'diffusion of innovative knowledge as a form of collective action requires social organisation' [9, p.301] that also requires 'an interactive process' involving 'different collective actors'. [9, p.301] For those more closely interested in the 'network paradigm' Borgatti and Foster provide an interesting review and typology. [10]

So is this an opportunity for a professional College to extend its reach through likeminded people engaging together, across both organisational and geographic boundaries [11] to extend their learning and to develop greater knowledge about improving leadership and health management practice in a collaborative distributed manner. 'Knowledge generation in networks of practice needs to be informed by a sense of community' and needs 'the umbrella element of communities of practice' [12] to provide the technology structure, resources and some level of governance.

The vision shown in the history of the College reflects like-minded people and communities of practice, health managers coming together across state and territory boundaries and health systems to establish a national organisation. This vision was similarly extended by practice and boundaries into the Asia Pacific through collaboration with similar organisations. Is the concept of DNoP a possible vision and compelling option to extend the professionalism of health management and the co-creation of health management knowledge through a more global focus? [13] Is their sufficient interest 'out there' to test the concept?

\section{DS Briggs}

Editor

Dr DS Briggs is a former National President of ACHSM and is currently President of SHAPE.

\section{References}

1. WHO 2014. Statement on advancing implementation research and delivery science. Alliance for Health Policy and Systems Research. Available from: Health Systems Global http://www.healthsystems global.org/the-irds-statement/

2. Lavis JL, Lomas J, Maimunah $\mathrm{H}$, Sewankambo NK. Assessing country level efforts to link research into action. Bulletin of the World Health Organisation. August 2006

3. Australasian College of Health Service Management. Website available from: https://www.achsm.org.au/Public/Home/Public/_ Default.aspx?hkey=1d04c553-b8d3-4692-8bc4-b8f87cc8c7c2. 2016

4. MG Harris and Associates. Managing Health Services: Concepts and Practice. 2nd ed. Sydney: Elsevier Australia; 2006.

5. Health Systems Global. Available from: http://www.healthsystems global.org/June 2016.

6. Hsia TL, Lin LM, Wu JH, Tsai HT. A framework for designing nursing knowledge management systems. Interdisciplinary Journal of Information, Knowledge and Management. 2006;1(13-22).

7. Hustad E. Exploring knowledge work practices and evolution in distributed networks of practice.

8. Agterberg M, van den Hooff B, Huysman M, Soekijad M. Journal of Management Studies. 2010; 47(1):85-108. 
9. Van Baalen P, Bloemhof-Ruwaard J, Van Heck E. Knowledge sharing in an emerging network of practice: the role of a knowledge portal. European Management Journal. 2005; 23(3):300-314. Doi:10.1016/j.emj.2005.04.008

10. Borgatti SP, Foster PC. The network paradigm in organisational research: a review and typology. Journal of Management. 2003; 29(6):991-1013.
11. Carlile PR. A pragmatic view of knowledge and boundaries: Boundary objects in new product development. Organisation Science. 2002;13(4):442-455.

12. Garcia BC. Global KBD community developments: the MAKCi experience. Journal of Knowledge Management. 2008;12(5).

13. Garcia BC. Making MAKCi. An emerging knowledge-generative network of practice in the Web 2.0. The Journal of Information and Knowledge Management Systems. 2010; 40(1):39-61.

\section{INVITATION}

\section{What problem is being solved?}

An invitation to submit an article to a special issue of the Asia Pacific Journal of Health Management (APJHM) entitled 'Critical issues in health systems management'.

What critical issue(s) in health systems management do we need to address to improve the healthcare outcomes of patients, communities, States/Provinces and Nations?

\section{Context}

It is more than a decade since the question What problem (in respect to health system restructuring) is being solved? [1] was proposed.

Most health systems continue to be restructured or be modified without much thought to underlying public policy. Health systems shift from perspectives of health being seen as a public good to a series of products being delivered in competitive markets through insurance systems, fundholding and commissioning. Services are privatised and/or delivered by non-government organisations. Acute care continues to be delivered in large centralised systems sometimes described as 'local', often funded historically despite the availability of tested casemix systems. Patient safety, quality and innovation are monitored through a range of state/province and national agencies while performance measures and outcomes are regularly measured and the results published. Primary healthcare, in many systems, remains fragmented. We seem to be transfixed about the implications of ageing populations and the chronic disease burden. Communities with poor socio-economic indicators do not seem to respond to current traditional health services and this raises the question of where the boundaries of healthcare might necessarily be drawn?

Within the system we manage through the strong personal commitment of health professionals with the hope that the language we use will bring needed change and improved healthcare delivery.
Our narrative is about greater use of technology, e-health, electronic records, a focus on 'avoidable admissions', evidence-based practice, clinical pathways, hospital in the home and patient-centred care, healthy ageing and innovation at all levels. Meanwhile, our research scientists and research institutions continue to stretch the boundaries of care and cure and, perhaps prevention, beyond that previously thought possible. International comparisons suggest that despite the context many are performing well!

\section{The invitation}

\section{What do you think are the critical issue(s)?}

We invite you to provide a perspective in an article that addresses a critical issue(s) in health systems management. Research articles, research notes, review articles and analysis of management practice are welcomed and contributions from across health systems will be appreciated.

Contributors' guidelines are available as a PDF at: https://www.achsm.org.au/Public/Resources/Journal/ Submit_an_article_/Public/Resources/Journal/Invitation_ to_Submit_an_Article.aspx?hkey=45e4c822-a3d2-423e965ed335afa1dfd4

The deadline for contribution from invited authors for peer review is September 30, 2016. Abstracts provided earlier would assist. Contributions from other authors would be appreciated with earlier submission dates appreciated by 30 August, 2016. Advice to the Editor that authors are intending to submit as soon as possible will assist.

Regards

\section{David Briggs}

Editor

1. Dwyer JM. Australian health system restructuring - what problem is being solved? Australia and New Zealand Health Policy. 2004;1:6. 